\title{
Generation of Reelin-Positive Marginal Zone Cells from the Caudomedial Wall of Telencephalic Vesicles
}

\author{
Keiko Takiguchi-Hayashi, ${ }^{1}$ Mariko Sekiguchi, ${ }^{1}$ Shizuko Ashigaki, ${ }^{1,3}$ Masako Takamatsu, ${ }^{3}$ Hiroshi Hasegawa, ${ }^{3}$ \\ Rika Suzuki-Migishima, ${ }^{2}$ Minesuke Yokoyama, ${ }^{2}$ Shigetada Nakanishi, ${ }^{4,5}$ and Yasuto Tanabe ${ }^{1,3}$ \\ ${ }^{1}$ Translational Research Department, Molecular Bio-Medicine Unit, ${ }^{2}$ Mouse Genome Technology Center, and Precursory Research for Embryonic Science \\ and Technology, Japan Science and Technology, Mitsubishi Kagaku Institute of Life Sciences, Machida, Tokyo, 194-8511, ${ }^{4}$ Department of Biological \\ Sciences, Faculty of Medicine, and ${ }^{5}$ Department of Molecular and System Biology, Graduate School of Biostudies, Kyoto University, Kyoto 606-8501, Japan
}

An early and fundamental step of the laminar organization of developing neocortex is controlled by the developmental programs that critically depend on the activities of reelin-positive cells in the marginal zone. However, the ontogeny of reelin-positive cells remained elusive. To gain insights into the spatial and temporal regulation of reelin-positive marginal zone cell development, we used a transgenic mouse line in which we defined the green fluorescent protein (GFP) transgene as a novel reliable molecular marker of reelin-positive marginal zone cells from the early stages of their development. We further used exo utero electroporation-mediated gene transfer that allows us to mark progenitor cells and monitor the descendants in the telencephalon in vivo. We show here the generation of reelinpositive marginal zone cells from the caudomedial wall of telencephalic vesicles, including the cortical hem, where the prominent expression of GFP is initially detected. These neurons tangentially migrate at the cortical marginal zone and are distributed throughout the entire neocortex in a caudomedial-high to rostrolateral-low gradient during the dynamic developmental period of corticogenesis. Therefore, our findings on reelin-positive marginal zone cells, in addition to the cortical interneurons, add to the emerging view that the neocortex consists of neuronal subtypes that originate from a focal source extrinsic to the neocortex, migrate tangentially into the neocortex, and thereby underlie neural organization of the neocortex.

Key words: Cajal-Retzius cells; neocortex; cerebral cortex; laminar organization; tangential cell migration; caudomedial-rostrolateral axis

\section{Introduction}

In the developing neocortex, the generation of distinct classes of cortical neurons is controlled by the hierarchical series of cellular interactions that culminate in the areal and laminar organization of distinct cortical areas. After the final cell mitosis, postmitotic cortical neurons migrate in a radial direction from the ventricular zone (VZ), form a cortical plate (CP), and subdivide the preexisting preplate into the superficial marginal zone (MZ) and the deeper subplate (Gupta et al., 2002; Nadarajah and Parnavelas, 2002). reelin-positive cells (Meyer et al., 1999) are one of the major neuronal subtypes located in the $\mathrm{MZ}$ and are distributed

\footnotetext{
Received 0ct. 16, 2003; revised Dec. 28, 2003; accepted Jan. 6, 2004.

This work was supported by grants from Precursory Research for Embryonic Science and Technology in Japan Science and Technology (to Y.T.). We thank S. Kamijyo, M. Matsuo, T. Akiyama, N. lizawa, T. Hino, and M. Takabe at Mitsubishi Kagaku Institute of Life Sciences Mouse Facility for their assistance. We also thank N. Osumi at Tohoku University for anti-Pax6 antibody, S. Yasugi and K. Fukuda at Tokyo Metropolitan University, K. Tamura at Tohoku University, and R. Kageyama and H. Yamazaki at Kyoto University for their kind advice in ISH technique, K. Arishima and T. Takizawa at Azabu University and H. Ohtani and T. Hatta at Simane Medical University for their kind advice on mouse surgery, S. C. Fujita at MITILS for anti-GFP antibody (Ab), Y. Yamakuni at MITILS for anti-calbindin Ab, N. Sugou at Osaka University for mouse Tbr1, Y. Hatanaka at Osaka University for PCAGGs-EGFP, I. Saitou at University of Tokyo for pCAGGS-LacZ, J. Miyazaki at Osaka University for PCAGGS, and S. Arber at University of Basel for NLS-LacZ. Y.T. thanks Dr. Watanabe at Kyoto University for the initial collaborative work. We thank S. Narita, A. Kudo, S. Nishimiya, and Y. Tsunekawa for their technical support. We are grateful to S. Goto, M. Setou, and T. Takeuchi at MITILS and T. M. Jessell at Columbia University for their thoughtful comments on a previous version of this manuscript.

Correspondence should be addressed to Dr. Yasuto Tanabe, 11 Minami-0oya, Machida, Tokyo, 194-8511, Japan. E-mail:ytanabe@libra.Is.m-kagaku.co.jp.

DOI:10.1523/JNEUROSCI.4671-03.2004

Copyright $\odot 2004$ Society for Neuroscience $\quad$ 0270-6474/04/242286-10\$15.00/0
}

evenly throughout the entire cerebral cortex in a wide variety of mammalian species (Marín-Padilla, 1998; Supèr et al., 1998). The analyses of reeler mutant mice (Ogawa et al., 1995; Meyer et al., 1999; Rice and Curran, 2001; Tissir and Goffinet, 2003), together with studies in human congenital lissencephaly (Gleeson and Walsh, 2000), led to the suggestion that the neocortical neural organization depends on the activities of reelin-positive cells that govern the laminar arrangements of CP cells from the early stages of development. Studies on how reelin-positive cell generation is spatially and temporally controlled in the telencephalon might, therefore, provide a solid cellular framework for understanding neural organization during development of the neocortex.

Despite many advances in the characterization of the way $\mathrm{CP}$ neurons are generated and organized into distinct layers (Gupta et al., 2002; Nadarajah and Parnavelas, 2002), the ontogeny of reelin-positive cells has remained elusive. The concept of a dual origin of the cerebral cortex, together with the classical concept from the time of Ramón y Cajal, provided a prevailing view that both reelin-positive cells and subplate are generated as preplate from the underlying VZ before the formation of CP (MarínPadilla, 1978, 1998). Consistent with these ideas, several studies suggest the local generation of reelin-positive cells within the neocortical area (Meyer et al., 2000; Hevner et al., 2003). In contrast, several lines of evidence suggest that neocortical reelinpositive cells may originate from locations extrinsic to the neocortex (Meyer et al., 1998, 2002; Lavdas et al., 1999; Shinozaki et al., 2002). Together, these studies raised the possibility that neo- 
cortical reelin-positive cells consist of heterogeneous cell groups that are generated at varied locations in the telencephalon, both extrinsic and intrinsic to the neocortex (Meyer et al., 2002). However, there is no direct evidence for those cells that have been generated at the putative sources to comprise reelin-positive cells located in the MZ of the neocortex. Moreover, the extent to which prospective reelin-positive cells from distinct sources contribute within the entire population of reelin-positive cells remains obscure. In addition, the way in which prospective reelinpositive cells from distinct sources are distributed throughout the entire cerebral cortical MZ remains to be defined in vivo. We show here prospective reelin-positive cells are generated from the caudomedial wall of telencephalic vesicles (CMWT) and exhibit the extensive tangential migration throughout the neocortical $\mathrm{MZ}$ in a caudomedial-rostrolateral cellular gradient.

\section{Materials and Methods}

Mice. C57BL/6 Tg mice (Watanabe et al., 1998) and ICR Jcl mice (CLEA Japan, Inc., Tokyo, Japan) were used for the experiments. Each strain was mated to obtain offsprings in house in an environmentally controlled room under the Guidelines for Use of Laboratory Animals (Japan Neuroscience Society) and the Animal Care and Use Committee (Mitsubishi Kagaku Institute of Life Sciences). Noon of the date on which the vaginal plug was detected in the morning was designated as embryonic day (E) 0.5.

Immunohistochemistry and in situ hybridization. Embryos were fixed by cardiac perfusion with $4 \%$ paraformaldehyde (PFA), $7 \%$ picric acid in $0.1 \mathrm{M}$ sodium phosphate buffer, $\mathrm{pH} 7.4$, for immunohistochemistry (IH), and with 4\% PFA in $0.1 \mathrm{M}$ sodium phosphate buffer, $\mathrm{pH} 7.4$, for in situ hybridization (ISH). The brain was postfixed in the fixative for $2 \mathrm{hr}$ for IH and for overnight for ISH. Samples were then equilibrated in $25 \%$ of sucrose in PBS and embedded in OCT compound (Sakura, Tokyo, Japan). Frozen sections were cut with a cryostat (MICROM HM500OM; Carl Zeiss, Oberkochen, Germany) at $10 \mu \mathrm{m}$ and mounted onto MAScoated glass slides (Matsunami, Osaka, Japan).

Immunohistochemical staining was performed as described (Takiguchi-Hayashi et al., 1998). Primary antibodies (Abs) used were: polyclonal rabbit anti- $\beta$ galactosidase $\mathrm{Ab}$ (Cappel, Worthington, $\mathrm{PA}$ ) in 1:1000; monoclonal rat anti-GFP (JFP-K2, kindly provided by Dr. S. C. Fujita) supernatant, polyclonal rabbit anti-calbindin $\mathrm{Ab}$ (spot 35, kindly provided by Dr. T. Yamakuni) in 1:1000, polyclonal rabbit anticalretinin $\mathrm{Ab}$ (Chemicon, Temecula, CA) in 1:1000, polyclonal rabbit anti-Pax6 Ab (kindly provided by Dr. N. Osumi) in 1:1000. Secondary Abs used were FITC-conjugated goat anti-rat IgG (AP183F; Chemicon) in 1:100, and cyanine3 (Cy3)-conjugated anti rabbit IgG (Jackson ImmunoResearch, West Grove, PA) in 1:400.

RNA probes prepared were EGFP (kindly provided by Dr. Watanabe), reelin (EcoRI/XhoI 1100bp fragment), p73 (XM 131858; GenBank, 1503-2232 nucleotides), and Lhx6 (AJ000337; GenBank, 6-651 nucleotides), Tbr1 (U49251; GenBank, 2951-3780 nucleotides), and Emx2 (AY117415; GenBank, 1385-1904 nucleotides). ISH was performed as described (Schaeren-Wiemers and Gerfin-Moser, 1993; Ishibashi et al., $1995)$ with minor modifications. For double-ISH, digoxygenin-UTP, and fluorescein-UTP (Roche Products, Hertforshire, UK) were used for labeling of the probes, and hybridization was performed simultaneously according to the procedures described in the manufacturer's protocol (TSA Biotin system; PerkinElmer Life Sciences, Emeryville, CA).

Axiovert 200M (Carl Zeiss, Jena, Germany), Olympus BX61 with a CCD camera DP50 (Olympus, Tokyo, Japan), and LSM5 PASCAL confocal microscope (Carl Zeiss) were used to obtain fluorescent images. The images were processed using Photoshop software (Adobe Systems, San Jose, CA).

$X$-gal staining. Embryos were fixed by cardiac perfusion with PBS containing $1 \%$ of formaldehyde, $0.2 \%$ of glutaraldehyde, and $0.02 \%$ of $\mathrm{NP}-40$ for $2 \mathrm{hr}$. X-gal staining procedures for whole-mount brain or frozen sections were performed as described (Motoyama et al., 1997).

BrdU labeling study. For birth date studies, timed-pregnant $\mathrm{Tg}$ mice to which in vitro fertilized eggs were transferred in utero were injected in- traperitoneally three times in $3 \mathrm{hr}$ intervals with BrdU (Roche; $5 \mathrm{mg} / \mathrm{ml}$ in sterile saline) at $50 \mathrm{mg} / \mathrm{kg}$ body weight on several stages of pregnancy. The date of injections was set at ages of E10.5 $(n=3)$, E11.5 $(n=3)$, $\mathrm{E} 12.5(n=2)$, and $\mathrm{E} 13.5(n=3)$. The pregnant mice were maintained for several days afterwards to obtain the embryos aged at E18.5, when the embryos were processed for $\mathrm{IH}$. Sections were first autoclaved at $110^{\circ} \mathrm{C}$ for $10 \mathrm{~min}$ in $0.1 \mathrm{M}$ sodium citrate buffer, $\mathrm{pH}$ 6.0, as described (Imam et al., 1995). BrdU and GFP were detected using anti-BrdU Ab (Dako, Carpinteria, CA) and anti-GFP Ab as described (Arimatsu et al., 1999). All the nuclei of BrdU-labeled cells, including both heavily and lightly labeled cells, were counted for the analysis.

Exo utero electroporation. cDNA fragments of NLS-LacZ (kindly provided by Dr. S. Arber) were subcloned into the $p C A G G s$ vector (kindly provided by Dr. J. Miyazaki). $p C A G G S-E G F P$ (kindly provided by Dr. Y. Hatanaka) and $p C A G G S$-LacZ (kindly provided by Dr. I. Saitou) were also used. Exo utero surgery was followed as described (Muneoka et al., 1986a,b; Ngo-Muller and Muneoka, 2000) with modifications.

We prepared embryos in exo utero condition to transfer genes more reliably to the focal region by electroporation. Timed pregnant mice at E11.5 were deeply anesthetized with sodium pentobarbital (Nembutal; Abbott, North Chicago, IL) at $50 \mathrm{mg} / \mathrm{kg}$ body weight. A midline abdominal incision was made on the pregnant mouse, and then both horns of uterus were exposed. The number of embryos in each horn was recorded, and then three embryos in each horn were selected, and the rest of the embryos were removed from the horns of the uterus to obtain enough space for the subsequent electroporation procedures. The selected three embryos were released from the constraints of myometrium by making a longitudinal incision in the uterine myometrium at a position opposite to the side of the placenta. The myometrium contracted to the base of the placenta, and the embryos covered with their thin extraembryonic membranes were exposed. DNA solutions $(5 \mathrm{mg} / \mathrm{ml}$ in $10 \mathrm{~mm}$ Tris- $\mathrm{HCl}, \mathrm{pH}$ 8.0, with $0.016 \%$ Trypan Blue to permit visualization of injected solution in the embryos) were injected into the left side of the lateral ventricle of E11.5 telencephalon with a glass micropipette. After the injection, the embryos covered with the extraembryonic membranes were held with the tweezer-type electrode with discs of $3 \mathrm{~mm}$ in diameter at the tip (CUY650P3; Nepa Gene Company, Chiba, Japan). Electronic pulses of $25 \mathrm{~V}$ were charged five times at $950 \mathrm{msec}$ intervals using a square-pulse electroporator (CUY21EDIT; Nepa Gene Company). For the electroporation aiming for the CMWT-directed gene transfer, the anode was positioned caudomedially so that the DNA is incorporated into the VZ cells of the CMWT. Likewise, the anode was always positioned on the direction to which the electroporation was conducted (see supplemental Figs. 2-4, available at www.jneurosci.org). After the procedures, embryos were placed back into the abdominal cavity of the pregnant mouse without sewing the uterine wall. The abdominal cavity was filled with prewarmed HBSS (Invitrogen, Gaithersburg, MD). Then, the abdominal wall was sewed with surgical sutures, and the skin was sewed with Autoclip applier (MikRon, Sparks, MD) to allow the embryos to develop. The pregnant mice were maintained for several days, and the embryos at E12.5-E18.5 were subjected to the analyses.

The focal restriction of electroporation-mediated gene transfer and its reproducibility was confirmed by the series of experiments shown in supplemental Figures 2-4 (available at www.jneurosci.org). For example, LacZ electroporation at E11.5 aimed for the CMWT was conducted in 12 embryos in total, among which eight embryos survived until E12.5, and all the eight embryos exhibited the focal restriction of gene transfer at the CMWT. In addition, when we analyzed 11 anterior-pole electroporated samples, 3 lateral wall electroporated samples, and 9 CMWT electroporated samples of E14.5 embryos, all the electroporated samples exhibited the focal LacZ expression in the ventricular zone adjacent to the electroporated region (see Fig. 4).

Slice cultures. Brains were embedded in $4 \%$ low-melting agarose gel, and $300-\mu \mathrm{m}$-thick parasagittal or oblique sections were cut on a vibratome, as shown in Figure 7l. Slices were then transferred to collagencoated culture membranes (Millicell-CM; $30 \mathrm{~mm}$ in diameter, $0.4 \mu \mathrm{m}$ pore size; Millipore, Bedford, MA) in organ tissue culture dishes containing $1.3 \mathrm{ml}$ of medium (Invitrogen; MEM-F-12 with glutamine, 5\% PNCS, 5\% horse serum, penicillin, and streptomycin) as described (Ari- 
matsu et al., 1992). They were subsequently cultured for several hours in sterile condition in an incubator $\left(5 \% \mathrm{CO}_{2}\right.$, at $\left.37^{\circ} \mathrm{C}\right)$, after which the medium was changed to Neurobasal/B-27 (Invitrogen). During the culture period, images of GFP fluorescent were captured by AxioCam MRm CCD camera with Zeiss Stemi SVII microscope (Carl Zeiss) at appropriate time intervals.

\section{Results}

Embryonic reelin-positive cells at the neocortical marginal zone are marked by GFP expression

Our study in $I G 17$ transgenic mice ( $T g$ mice) (Watanabe et al., 1998) revealed that the membrane-anchored GFP transgene is specifically expressed by reelin-positive cells in the MZ during the early postnatal period (Soda et al., 2003). This observation prompted us to examine whether the GFP transgene can be used as a novel marker for the embryonic reelin-positive cells and to analyze the ontogeny of reelin-positive marginal zone cells in the early embryonic stages of neocortical development. We first examined whether embryonic GFP expression is restricted to the reelin-positive cells in $\mathrm{Tg}$ mouse telencephalon. Murine embryonic reelin-positive cells can be characterized by the uniform location of cell bodies in the MZ, neurite extensions in a tangential direction, and the early onset of generation compared with the CP neurons (Supèr et al., 1998). We analyzed the telencephalon of $\mathrm{Tg}$ mouse embryos from E14.5 onward, by which time the neocortical MZ has emerged, and reelin-positive cells have acquired their characteristic identities (Wood et al., 1992; Polleux et al., 1997).

We first defined the pattern of GFP expression in $\mathrm{Tg}$ mouse telencephalon. At E14.5, GFP expression was detected in the MZ of all the rostrocaudal levels of the cerebral cortex (Fig. 1a-c). Intensive GFP expression in the MZ encompassed nearly the entire cerebral cortex, including the neocortex, the piriform, the cingulate cortex (Fig. $1 a-c$ ), and the dorsal and ventral regions adjacent to the choroid plexus (Fig. $1 b, c$ ). From E16.5 onward, although the MZ itself was expanded, the pattern of GFP expression remained essentially similar and persisted until the latest age examined (E18.5) (Fig.1e,f) (data not shown). GFP-expressing cell bodies were embedded in tangentially oriented intricate nerve fibers in the MZ (Fig. $1 d-f$ ).

We next analyzed the pattern of GFP expression within the neocortical $\mathrm{MZ}$ in relation to the molecular markers that have been used to define the major types of $M Z$ cells, including the reelin-positive cells. Reelin and p73 serve as reliable markers of reelin-positive cells from the early stages of their development (Schiffmann et al., 1997; Alcantara et al., 1998; Meyer et al., 2002). Lhx6 marks other neuronal subtypes in the murine neocortical MZ (Lavdas et al., 1999). Double in situ analyses of GFP with reelin at E14.5-18.5 revealed that virtually all the GFPpositive cells located at the neocortex coexpressed reelin, and vice versa (Fig. 1g-i) (data not shown). Similarly, virtually all the GFP-positive cells were colabeled by $p 73$ in the neocortical MZ at E14.5-18.5 (Fig. 1j-l) (data not shown). On the contrary, the double in situ analyses of GFP in relation to $L h x 6$ revealed that, at E14.5, the expression of GFP and $L h x 6$ was mutually exclusive in the neocortical MZ (Fig. 1 $m-o$ ). Double in situ hybridization of Emx2 and Tbr1 in relation to GFP revealed that the expression of Emx2 and Tbr1 was evident in virtually all of the GFP-positive cells in the marginal zone of the neocortex at E14.5 (supplemental Fig. 1, available at www.jneurosci.org). Confocal microscopic analyses of double immunostaining of Pax6 in relation to GFP revealed that Pax6 expression was evident in some of the GFPpositive cells in the marginal zone of E14.5 neocortex. Previous
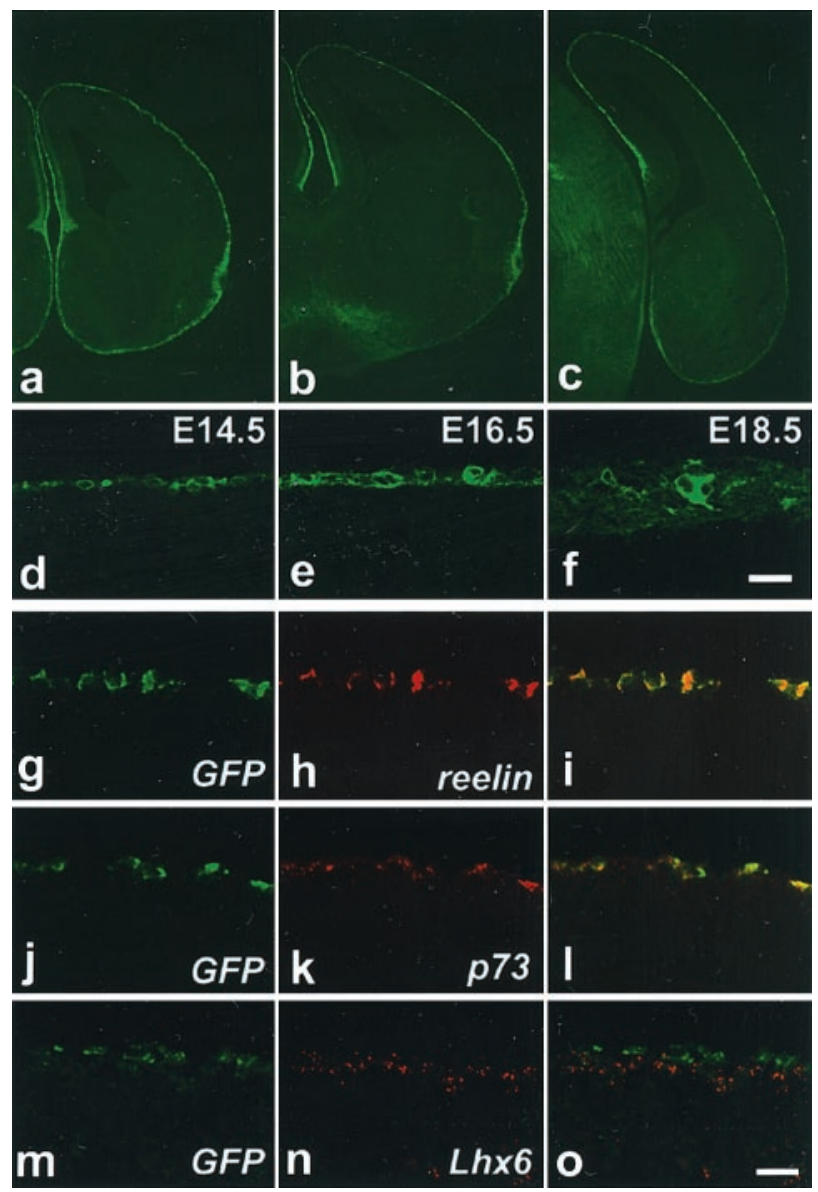

Figure 1. Expression of GFP by reelin-positive cells at the neocortex of $\mathrm{Tg}$ mouse embryos. $a-c$, Coronal sections at the anterior $(a)$, intermediate $(b)$, and posterior $(c)$ levels of E14.5 cerebral cortex showing the restricted expression of GFP in the entire MZ. $d-f$, Restriction of GFP in the neocortical MZ at E14.5 (d), E16.5 (e), and E18.5 ( $f) . g-0$, Double ISH analyses of GFP in green $(g, i, j, l, m, 0)$ with reelin in red $(h, i), p 73$ in red $(k, I)$, and $L h \times 6$ in red $(n, 0)$ of the E14.5 neocortical MZ. Scale bars, $20 \mu \mathrm{m}$.

studies show that most of the reelin-positive marginal zone cells at E14.5 express Emx2, and Tbr1, and some of them express Pax6 (Stoykova et al., 2003). Confocal microscopy studies of calretinin in relation to GFP revealed that calretinin expression was evident at E14.5 in most of the GFP-expressing cells in the marginal zone of the neocortex, but a few GFP expressing cells were negative for the calretinin expression (supplemental Fig. 1, available at www.jneurosci.org). From E16.5 onward, however, there was a nearly complete overlap of GFP and calretinin expression in the marginal zone of neocortex (data not shown). These temporal expression profiles of GFP in relation to calretinin are consistent with the idea that the onset of GFP expression is before that of calretinin. Taking into account of fact that the onset of reelin expression also precedes that of calretinin in reelin-positive marginal zone cells, these data further support the notion that the expression pattern of GFP coincides with that of reelin in the $T g$ neocortex. Calbindin defines mostly non-reelin-positive cells at E14.5 cerebral cortical marginal zone. Consistent with this, nearly all of the calbindin staining was not detected in GFP-expressing cells in the neocortical marginal zone of E14.5 $\mathrm{Tg}$ mouse embryos (supplemental Fig. 1, available at www.jneurosci.org).

Together, these findings provide evidence that, at the neocortex, GFP is expressed exclusively by reelin-positive cells in the embryonic $\mathrm{Tg}$ telencephalon from E14.5 onward. These data 
demonstrate that GFP, in addition to reelin and p73, serves as another reliable molecular marker of reelin-positive cell identity in the embryonic $T g$ neocortical MZ.

\section{Birth date analyses of GFP-expressing cells at the neocortical MZ}

To substantiate the notion that GFP transgene at the neocortex marks reelin-positive cells exclusively, we examined the birth date of GFP-positive cells in the MZ by $5^{\prime}$-bromo- 2 ' deoxyuridine (BrdU) labeling studies. Progenitor cells at S-phase of the cell cycle were labeled in vivo by injecting BrdU into pregnant mice from E10.5 onward, and the BrdU-labeled GFP-positive cells were subjected to the immunocytochemical analyses at E18.5 (Fig. $2 a-c$ ). More than $90 \%$ of GFP-positive cells in the neocortical $\mathrm{MZ}$ were colabeled with BrdU that was injected at E10.5, indicating nearly all of the GFP-positive cells are generated from E10.5 onward (Fig. 2a, supplemental Table 1, available at www.jneurosci.org). The proportion declined as the date of injection was set at later embryonic ages and became $<4 \%$ at injection date of E13.5. These data indicate that $~ 53 \%$ of GFPpositive neocortical MZ cells were generated at E10.5-11.5, $29 \%$ at $\mathrm{E} 11.5-12.5, \sim 8 \%$ at $\mathrm{E} 12.5-13.5$, and the rest before $\mathrm{E} 10.5$ and/or after E13.5 (Fig. 2b; see also supplemental Table 1, available at www.jneurosci.org). It appears there was no regional difference in the neocortex along the dorsolateral axis for the temporal pattern of generation of GFP-positive cells (Fig. 2a). Previous studies dealing with the issue of timing of reelin-positive cell generation were able to show that most of the reelin-positive cells were generated at approximately E10.5-E12.5 in the murine telencephalon (Wood et al., 1992; Hevner et al., 2003). Thus, our BrdU labeling studies are consistent with the idea that, in the neocortex, GFP transgene is expressed exclusively by reelinpositive cells. Importantly, the fact that $40.3 \%$ of reelin-positive cells on average were generated from E11.5 onward (supplemental Table 1, available at www.jneurosci.org) allowed us to examine the origins of reelin-positive cells by using electroporationmediated gene transfer method at E11.5 (see below).

\section{Onset of GFP expression in relation to reelin and p73}

To begin to address the issue of ontogeny of reelin-positive cells, we examined the onset of expression of GFP in relation to those of reelin and $p 73$ in $\mathrm{Tg}$ mouse telencephalon (Fig. 3). Based on our BrdU labeling studies, we focused our analysis on E10.5-E11.5 when most of the reelin-positive cells were generated. We asked if the expression of GFP transgene could be detected before that of reelin or $p 73$, and the GFP transgene might serve as a tool to monitor the onset of reelin-positive cell generation.

At E10.5, prominent expression of GFP was first detected at the ventral region of CMWT at the rostrocaudal level where the telencephalon-diencephalon junction (TDJ) exists, merging apparently with the GFP expression at the diencephalon (Fig. $3 b, f$ ). GFP expression was detected in continuity at the subpial layer of ventral subpallium (Fig. 3b), including the GE primordium (Fig. $3 d, e)$. Some GFP-positive cells were scattered in the VZ at these locations, suggesting their local generation (Fig. $3 b, d-f$, arrows). In addition, a few GFP-positive cells were detected at the subpial layer of the prospective neocortex (Fig. $3 b, d$, arrowhead). In contrast, $p 73$ expression was detected at the dorsal region of CMWT and extended into the prospective neocortical areas (Fig. $3 a$, arrowheads). Some p73-expressing cells were detected even in the VZ of the CMWT (Fig. 3a, arrows) (Meyer et al., 2002). A few, if any, $p 73, G F P$, and reelin-positive cells were also scattered in the $\mathrm{VZ}$ of the neocortical primordium (Fig. $3 a$, data not shown).
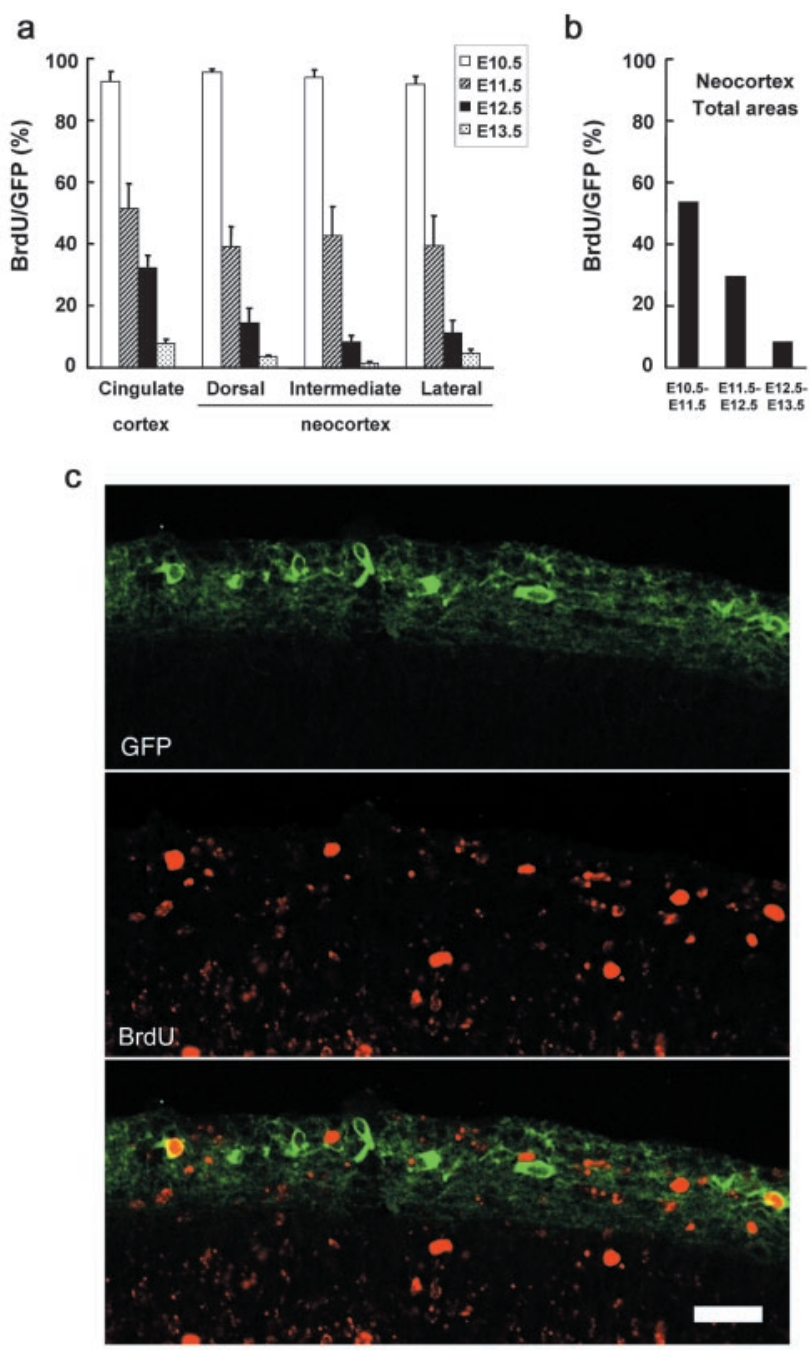

Figure 2. Birth date analyses of GFP-positive cells in the cerebral cortical MZ by the BrdU labeling study. a, Quantitative analyses of the proportion of the number of BrdU and GFP coexpressing cells in the total number of GFP-expressing cells in E18.5 cerebral cortical MZ. Data points represent mean values \pm SE from $>160$ cells. Neocortical MZ was divided into three areas along the dorsolateral axis. There was no significant regional difference in the generation of GFP-positive cells among the three regions. The temporal pattern of generation of GFPpositive cells at the cingulate cortex was similar to that of neocortex. All the BrdU-labeled cells, including both the heavily labeled and weakly labeled cells, were counted for the analyses. $b$, Summary of quantitative analyses of birth date of GFP-positive cells in the entire neocortical MZ. Data represent the proportion of the number of GFP-positive cells that are generated at each of the time windows. See supplemental Table 1 (available at www.jneurosci.org) for the detailed results of quantitative analyses. The percentage of GFP-positive cells generated in the three distinct regions of neocortex from E10.5 onward was $93.3 \%$ on average; the percentage of GFP-positive cells generated from E11.5 onward was $40.3 \%$ on average; the percentage of GFP-positive cells generated from E12.5 onward was $11.3 \%$ on average, the percentage of GFP-positive cells generated from E13.5 onward was $3.2 \%$ on average. By subtracting these numbers, we obtain, for example, $53 \%$ for the percentage of GFP-positive cells that are generated between E10.5 and E11.5 intervals. C, A representative coronal section showing the staining patterns of GFP and BrdU. A few number of GFP-, BrdU-double positive cells are shown. Scale bar, $20 \mu \mathrm{m}$.

At E11.5, the area of prominent GFP expression in the CMWT adjacent to the TDJ expanded in a bifurcated stream of cells (Fig. $3 h, k)$. It extended in both dorsal and ventral directions at the subpial layer of telencephalic vesicles: dorsally along the dorsal medial wall of telencephalon (Fig. $3 h, k$, arrowheads), and ventrally along the ventral subpallium (Fig. $3 h, k$, arrows). The expression of GFP at the ventral subpallium appeared to be followed by reelin expression, and accordingly, the area of reelin 


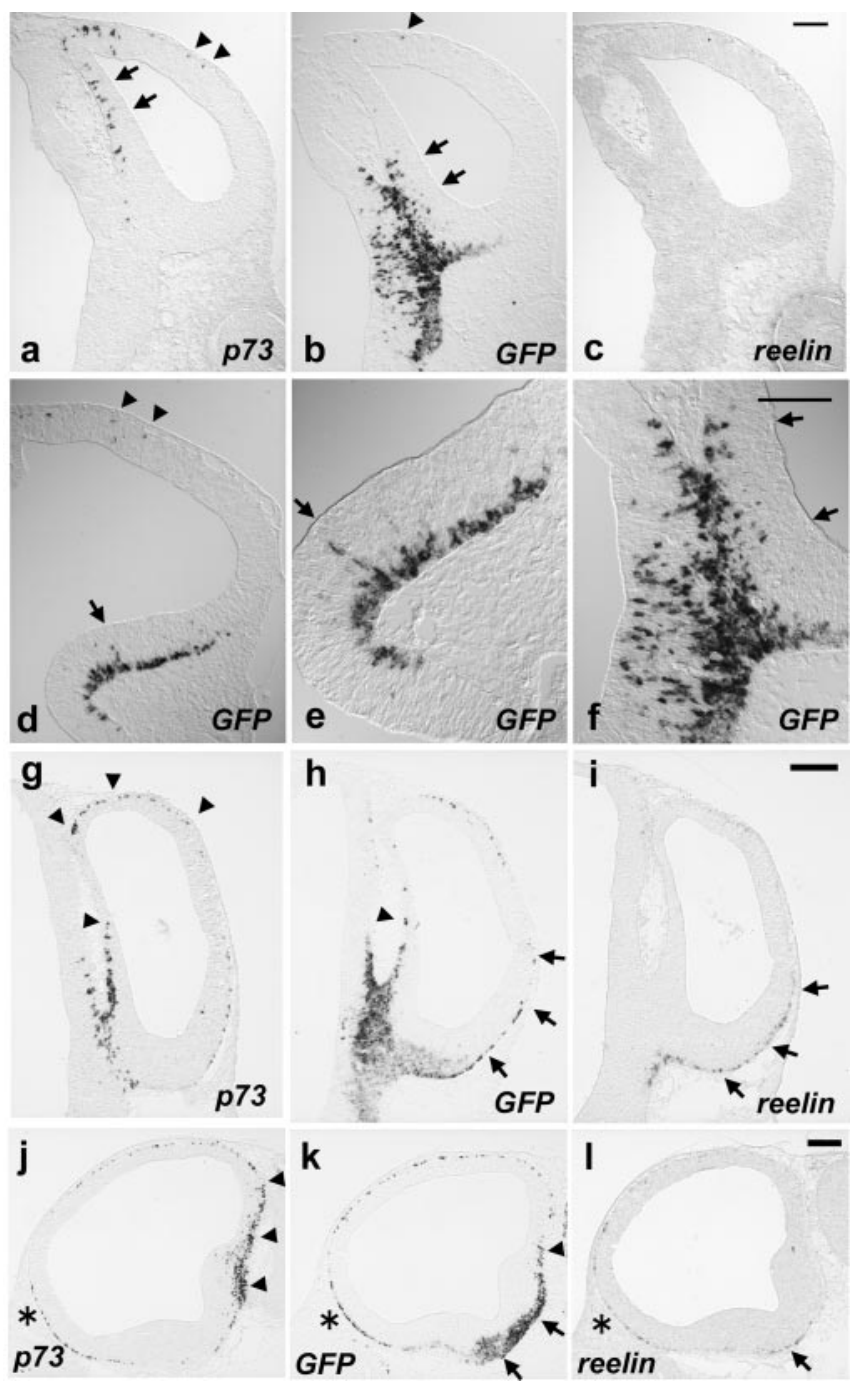

Figure 3. Onsets of $p 73, G F P$, and reelin expression in the telencephalon. ISH analyses of $p 73$ $(a, g, j), \operatorname{GFP}(b, d-f, h, k)$, and reelin $(c, i, l)$ at E10.5 $(a-f)$ and at E11.5 $(g-l)$. Coronal sections of telencephalon at the rostrocaudal level where the TDJ exists $(a-c, f-i)$, coronal sections at the rostrocaudal level where the $\mathrm{GE}$ primordium exists $(d, e)$, and parasagittal sections through the CMWT $(j-l)$ are shown. $e, f$, High-power views of $d$ and $b$, respectively. Rostral is to the left in $j-l$. Arrows in $a, b, d, e$, and $f$ show the VZstaining. Arrowheads in $a, b$, and $d$ show staining at the subpial layer of prospective neocortex. Arrowheads in $g, h, j$, and $k$ show gene expression at the dorsal part, whereas arrows in $h, i, k$, and / show gene expression at the ventral part of cerebral cortex. Scale bars: $a-f, 100 \mu \mathrm{m} ; g-l, 200 \mu \mathrm{m}$.

expression appeared to be contained within a broader area of GFP expression (Fig. $3 h, i, k, l$, arrows). Moreover, there was a graded distribution of GFP and reelin expression from ventral to lateral at the subpial layer of cerebral cortex (Fig. 3h, $i$, arrows). Conversely, the expression of $p 73$ at the dorsal region of CMWT appeared to be followed by that of GFP (Fig. $3 g, h, j, k$, arrowheads). In contrast to the GFP and reelin expression pattern, $p 73$ expression was distributed in a dorsal to lateral gradient at the subpial layer and appeared to emanate from the dorsal region of CMWT (Fig. 3g,j, arrows). p73, GFP, and reelin expressions were detected on the ventral cortical surface near the olfactory primordium (Fig. 3j-l, asterisks) (Meyer et al., 1998). By E12.5, all three genes were detected uniformly in the $\mathrm{MZ}$ of the cerebral cortex (data not shown).

Together, these results show the CMWT adjacent to TDJ is the region where most prominent expression of GFP is detected (Fig.
$3 b, f, h, k)$. Importantly, the expression of GFP at this locus was temporally overlapped with that of $p 73$ (Fig. $3 a, g, j$ ) and reelin (Fig. $3 c, i, l$ ). At the ventral region of CMWT, the onset of expression of GFP appeared to precede those of reelin and $p 73$, whereas, at the dorsal region of CMWT, the onset of expression of $p 73$ appeared to precede those of GFP and reelin (Fig. $3 a-c, g-l$ ). In contrast, the expression of reelin-positive cell markers in other telencephalic regions was relatively weak compared with the CMWT (Fig. $3 a-d, g-l$ ). In summary, over the major period of reelin-positive cell generation, the prominent expressions of GFP, reelin, and $p 73$ appeared to emanate from the CMWT into the neocortex. Therefore, these observations raised the possibility that the CMWT is a site where prospective CR cells are generated.

\section{Generation of prospective reelin-positive cells at the CMWT}

To establish a direct link between the cells generated at the CMWT and reelin-positive marginal zone cells at the neocortex in vivo, we used exo utero electroporation-mediated gene transfer to mark VZ cells at the CMWT by LacZ and to follow the LacZlabeled descendants. We focused our analysis on reelin-positive cells generated at E11.5, because the electroporation-mediated gene transfer can be carried out reliably and reproducibly onto the focal region under a microscope from E11.5 onward (supplemental Figs. 2-4, available at www.jneurosci.org). Plasmid DNA injection into the E10.5 embryonic telencephalic vesicles exo utero was hampered by the presence of deciduas surrounding the embryos, and the survival rate of embryos severely decreased by removing deciduas.

We first electroporated $L a c Z$ into cells located at the anteriorpole (Fig. $4 a, e, h$ ) or the lateral wall (Fig. $4 c, f, i$ ) of telencephalic vesicles at E11.5, permitted embryos to develop until E14.5, and analyzed the LacZ expression pattern. Most of the LacZ-positive descendants essentially remained at the neighboring regions where the electroporation-mediated gene transfer was conducted (Fig. 4a,c). The LacZ expression was confined, mostly to the VZ (Fig. $4 e, f$, arrows) and the CP, but barely, if any, to the $\mathrm{MZ}$ of the neocortex (Fig. 4e,f,h,i). In contrast, when we electroporated LacZ into cells located at the CMWT at E11.5, a population of LacZ-positive descendants was detected on nearly the entire cortical surface in a caudomedial-high to rostrolateral-low gradient at E14.5 (Fig. 4b,d). Coronal sections revealed intensive LacZ staining in the $M Z$ throughout the entire dorsoventral axis of the cerebral cortex (Fig. 4g,j). The VZ staining of LacZ was confined to the CMWT, which is consistent with the procedures of caudomedially directed electroporation of gene transfer (Fig. $4 g$, arrows). No staining was detected in the $\mathrm{CP}$, the subventricular or the $\mathrm{VZ}$ of any other regions of the telencephalon (Fig. $4 g, j$ ).

We then examined the identity of CMWT-derived LacZpositive descendants located in the $\mathrm{MZ}$ of the neocortex. We analyzed LacZ-positive cells with anti-GFP antibody at E14.5 after the electroporation of $L a c Z$ at E11.5 mouse (Fig. $4 k-m$ ). All the LacZ-positive cells detected in the MZ of the neocortex coexpressed GFP, indicating LacZ derivatives in the neocortex from the CMWT were solely reelin-positive cells. Moreover, these LacZpositive cells appeared to form a substantial population of reelinpositive cells, especially at the posterior neocortex (Fig. 4b,d).

Together, these findings indicate that virtually all of descendants derived from the CMWT at E11.5 comprise reelin-positive cells that were distributed widely in a caudomedial-rostrolateral gradient in the cerebral cortex at E14.5. Moreover, the other regions of telencephalon, including the neocortical primordium, where the electroporation was conducted appeared to give rise to a few, if any, reelin-positive cells at E11.5. 


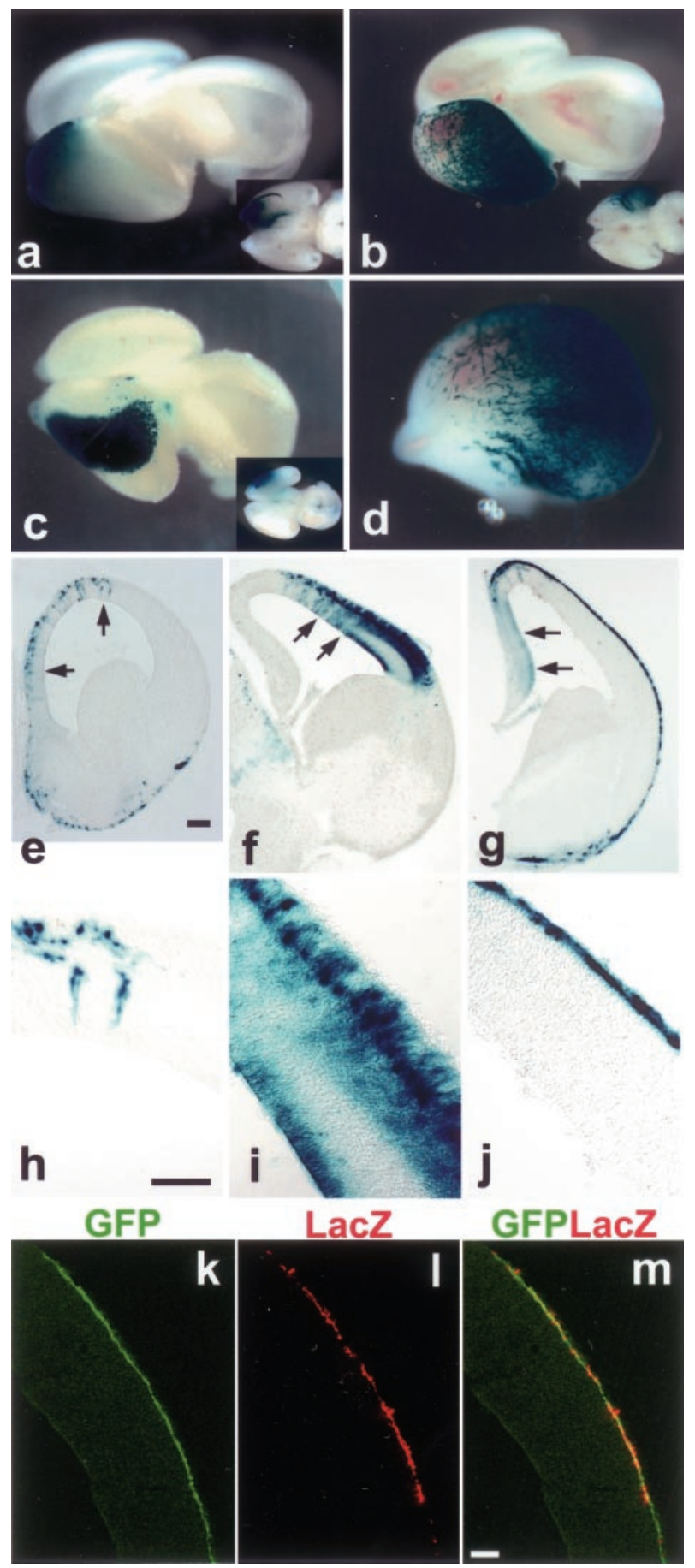

Figure 4. Generation and distribution of prospective reelin-positive cells derived from the CMWT. $a-d$, LacZ staining of E14.5 brains in whole-mount views. Electroporation was done into cells located at the anterior-pole $(a)$, the lateral wall $(c)$, or the caudomedial wall $(b, c)$ of telencephalic vesicles. Inset $(a-c)$, A ventral view. $d$, A lateral view shown in $b . e-j$, Coronal sections of E14.5 brain showing the pattern of LacZ staining. Images shown in $e$ and $h$ are obtained from the brain shown in $a$; $f$ and $i$ from $c ; g$ and j from $b$. Arrows $(e-g)$ show the LacZ staining in the VZ. $h-j$, High-power views of $e, f$, and $g$, respectively, showing the neocortical areas. Electroporation into the anterior-pole sometimes resulted in the LacZ distribution in the ventral cortical MZ $(a, e)$. Electroporation toward the CMWT exhibited only a faint, but significant, expression of LacZ at the invaginated medial wall (arrows in $g$ ), because of the LacZ staining has been performed in whole-mount preparation. Images are representative of 11 electroporated samples in $a, e$, and $h$, three electroporated samples in $c, f$, and $i$, and 9 electroporated samples in $b, d, g$, and $j$. Analyses of reproducibility of focal restriction of electroporation-mediated gene transfer at E14.5 revealed that all the electroporated samples exhibited the focal LacZ expression in the ventricular zone adjacent to the electroporated region. $k-m$, Double immunohistochemical analyses of GFP staining in green $(k, m)$ and LacZ staining in red $(l, m)$. Scale bars: $e-j, 100 \mu \mathrm{m} ; k-m, 50 \mu \mathrm{m}$.

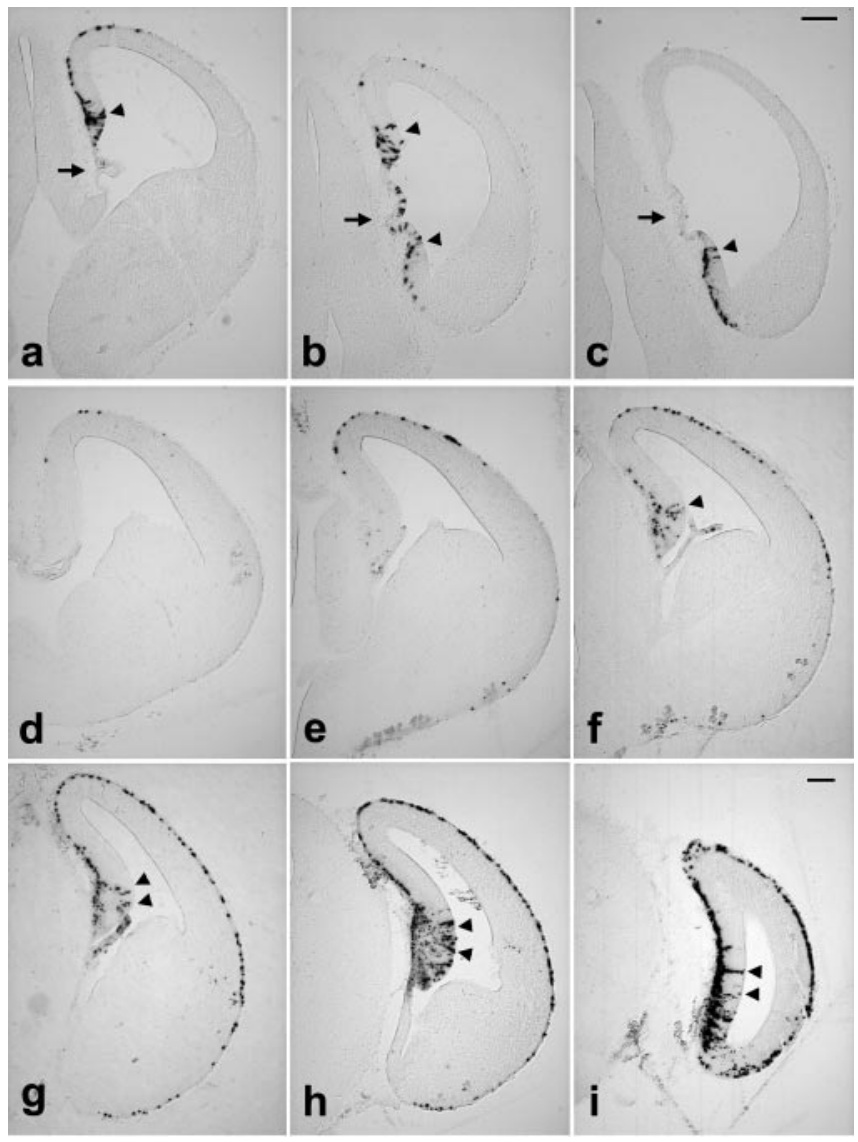

Figure 5. Origins and migratory routes of LacZ descendants at the CMWT. $a-c$, LacZ staining of coronal sections of 12.5 telencephalon at the level where $\mathrm{CP}_{\mathrm{P}}$ reside $(a-c)$. Arrows point the $C P_{p}$. Images are representative of eightelectroporated samples $d-i$. NLS-LacZstaining of serial coronal sections of E14.5 telencephalon from rostral to caudal levels $(d-i)$. Images are representative of five electroporated samples. Arrowheads in $d-i$ show the VZ staining. Scale bars, $200 \mu \mathrm{m}$.

\section{Origins and migratory pathways of prospective reelin- positive cells at the CMWT}

The persistence of LacZ staining in the VZ where the electroporation was conducted led us to examine the origins at the CMWT. The LacZ staining was performed on coronal sections of the telencephalon at E12.5 after the electroporation of LacZ into the CMWT at E11.5 (Fig. $5 a-c$ ). In all sections examined, the NLSLacZ staining in the MZ of the cerebral cortex was always correlated with the NLS-LacZ staining in the VZ of the CMWT region that most likely corresponded to the cortical hem. The cortical hem is characterized by its unique positions relative to the choroid plexus primordium $\left(\mathrm{CP}_{\mathrm{p}}\right)$ (Grove et al., 1998). At the more rostral level of cerebral cortex, the LacZ expression in the MZ of the dorsal cerebral cortex was always detected together with the ventricular LacZ expression dorsal to the $\mathrm{CP}_{\mathrm{P}}$, corresponding to the dorsal cortical hem ( $n=8$ independent electroporated embryos) (Fig. $5 a-c$ ) (Grove et al., 1998). In contrast, at the more caudal level of cerebral cortex where the cortical hem can be detected both dorsal and ventral to the $\mathrm{CP}_{\mathrm{P}}$, LacZ expression in the $\mathrm{MZ}$ of the ventral cerebral cortex was always detected together with the ventricular LacZ expression ventral to the $\mathrm{CP}_{\mathrm{P}}$, corresponding to the ventral cortical hem $(n=8$ independent electroporated embryos) (Fig. $5 a-c$ ). When either of these ventricular regions was negative for the LacZ staining, no staining was detected in the neighboring MZ (Fig. $5 a, c$ ).

Thus, the detailed analyses of the CMWT for the LacZ expres- 
sion pattern after $24 \mathrm{hr}$ of electroporation suggest that the cortical hem contributes to the generation of reelin-positive cells. Furthermore, these results obtained from the short time point after electroporation revealed the correlation between the origins and the direction of the initial pathways taken by the descendants. It appears that distinct pathways are taken initially by the prospective reelin-positive cells depending on the originated regions of the cortical hem. The prospective reelin-positive cells appear to take a dorsal route from the dorsal cortical hem, whereas a ventral route from the ventral cortical hem. We do not rule out the possibility, however, that CMWT regions outside of the cortical hem may also contribute to the generation of prospective reelinpositive cells.

This type of analysis also provided information on the extent of tangential migration of descendants that were derived from the cortical hem. To monitor the extent of tangential migration of descendants in the $\mathrm{MZ}$ of the cerebral cortex more precisely, we electroporated nuclear-localizing signals containing LacZ (NLSLacZ) at E11.5 to detect gene-incorporated cells and monitored NLS-LacZ expression pattern at E14.5. NLS-LacZ-positive descendants detected at E14.5 cerebral cortex covered most of the cerebral cortical MZ, including the cingulate cortex, the neocortex, the piriform, and the amygdala, with caudomedial-high to rostrolateral-low graded distribution ( $n=5$ independent electroporated embryos) (Fig. $5 d-i$ ). The NLS-LacZ staining in the $\mathrm{VZ}$ of the cerebral cortex was again detected at a region of the CMWT, which corresponded to the dorsal and posterior end of cortical hem (Fig. $5 d-i$ ). In addition, NLS-LacZ expression in the $\mathrm{VZ}$ was not detected in any other regions of the cerebral cortex. Thus, these results provide additional supportive evidence that the telencephalic neuroepithelium adjacent to the choroid plexus at the CMWT, cortical hem, have contributed to the generation of prospective reelin-positive cells. Moreover, these studies suggest that reelin-positive cells that are derived from the dorsal and posterior end of cortical hem at E11.5 are distributed throughout nearly the entire cerebral cortical MZ along its dorsoventral axis by E14.5.

\section{Tangential migratory behavior and localization of reelin- positive cells in the MZ of the cerebral cortex}

To further characterize the spatial and temporal patterns of in vivo migratory behavior of CMWT-derived LacZ-positive descendants in the $\mathrm{MZ}$, we monitored the sequential appearance of LacZ expression at the cerebral cortex in whole-mount preparation of the brain, after the electroporation of $L a c Z$ at E11.5 (Fig. $6)$. Focal restriction and reproducibility of electroporationmediate gene transfer was confirmed beforehand (see supplemental Figs. 2-4, available at www.jneurosci.org). At E12.5, most of the cells that had incorporated LacZ remained at the CMWT where electroporation was conducted (Fig. 6a). Only a few, if any, cells traversed the edge of CMWT circumferentially from dorsal, ventral, and posterior directions, and emerged at the lateral wall of the cerebral hemisphere (Fig. $6 a$, inset). At E13.5, many LacZpositive cells were located on the cortical surface along the entire dorsoventral axis of the posterior half of the cerebral cortex (Fig. $6 b)$. By E16.5, the entire cortical surface was covered by intensive LacZ staining, especially at the posterior cerebral cortex (Fig. 6c). The LacZ staining was also detected on the ventral cortical surface (Fig. $6 c$, inset), which was consistent with the observations of the migratory behavior of the LacZ descendants on E12.5 sections (Fig. 5h,I) (see also Fig. $4 b$, inset). There was a caudomedial-high to rostrolateral-low gradient in the distribution of LacZ-positive cell populations, as it was observed at E14.5 (Fig. 4b,d). The extent of anterior limit of LacZ-positive cells on the cortical surface

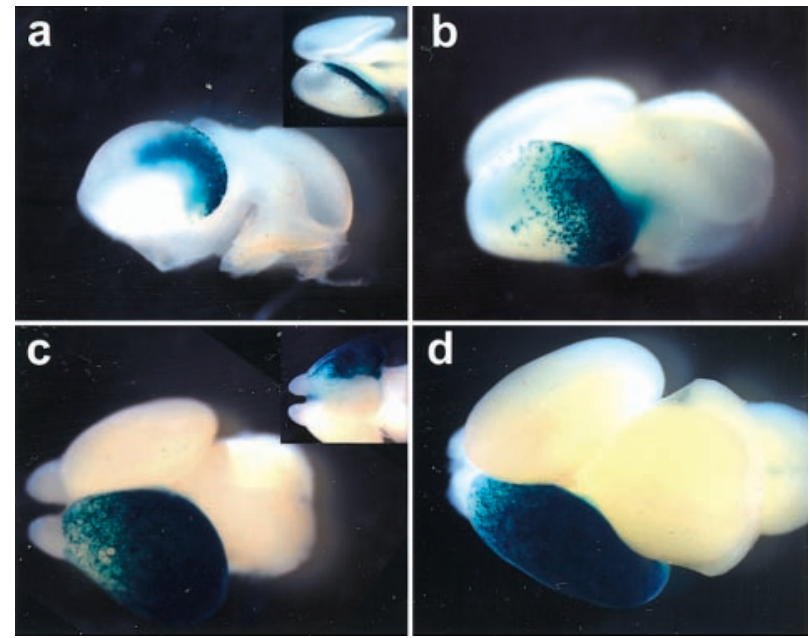

Figure 6. In vivo tangential migratory behavior of the CMWT-derived LacZ descendants. Whole-mount images showing the tangential migratory behavior of LacZ descendants on the cortical surface of E12.5 (a) ( $n=8$ : electroporated samples), E13.5 (b) $(n=4), \mathrm{E} 16.5$ (c) $(n=$ $5)$, and E18.5 $(d)(n=2)$ brains. Inset in a, A dorsal view. Inset in c, A ventral view.

remained essentially similar from E14.5 onward, suggesting that CMWT-derived reelin-positive cells at E11.5 may have reached at their final destination at around E14.5 (Figs. 4b,d, 6c). From E16.5 onward, LacZ-positive cells harbored extensive tangentially oriented neurites, a characteristic morphology of many of the matured reelin-positive cells (Fig. 6c). At E18.5, intensive LacZ staining covered the entire cerebral cortex in a gradient apparently similar to that observed from E14.5 onward (Fig. 6d).

Together, these results obtained from the in vivo studies provide evidence that a substantial population of prospective reelinpositive cells is generated at the CMWT, including the cortical hem at E11.5, and tangentially migrate to the MZ of the cerebral cortex. They traverse the edge of the CMWT circumferentially and appear at the lateral wall of the cerebral hemisphere to set up an overall posterior-anterior stream of cells. Subsequently, they are widely distributed throughout the entire neocortex in a caudomedial-high to rostrolateral-low gradient and, consequently, comprise a substantial population of reelin-positive cells located at the posterior neocortex.

\section{In vitro slice culture analyses of origins and migratory behavior of reelin-positive cells}

The in vivo analyses presented above, however, is retrospective in nature and do not rule out the possibility that LacZ-positive cells located in the neocortical MZ originated from locations where no LacZ staining remained after the in vivo culture period.

To rule out this possibility and to further examine the tangential migratory pathways taken by the CMWT-derived reelinpositive cells, we set up an in vitro slice culture experiment that allowed us to analyze the origins and migratory behavior of reelin-positive cells prospectively on time during the culture period (Fig. 7). We electroporated GFP into the CMWT of ICR mice at E11.5 and permitted embryos to develop in vivo until $24 \mathrm{hr}$ after the electroporation, when the level of gene expression is expected to be reached nearly at the peak. We isolated embryos and selected for the telencephalon in which GFP expression was detected only at the CMWT. Then, slices were prepared from the selected telencephalon (Fig. $7 l$ ), cultured in vitro, and were monitored on time for the migratory behavior of GFP-positive cells using GFP fluorescent. We prepared slices along the dorsolateral, pos- 


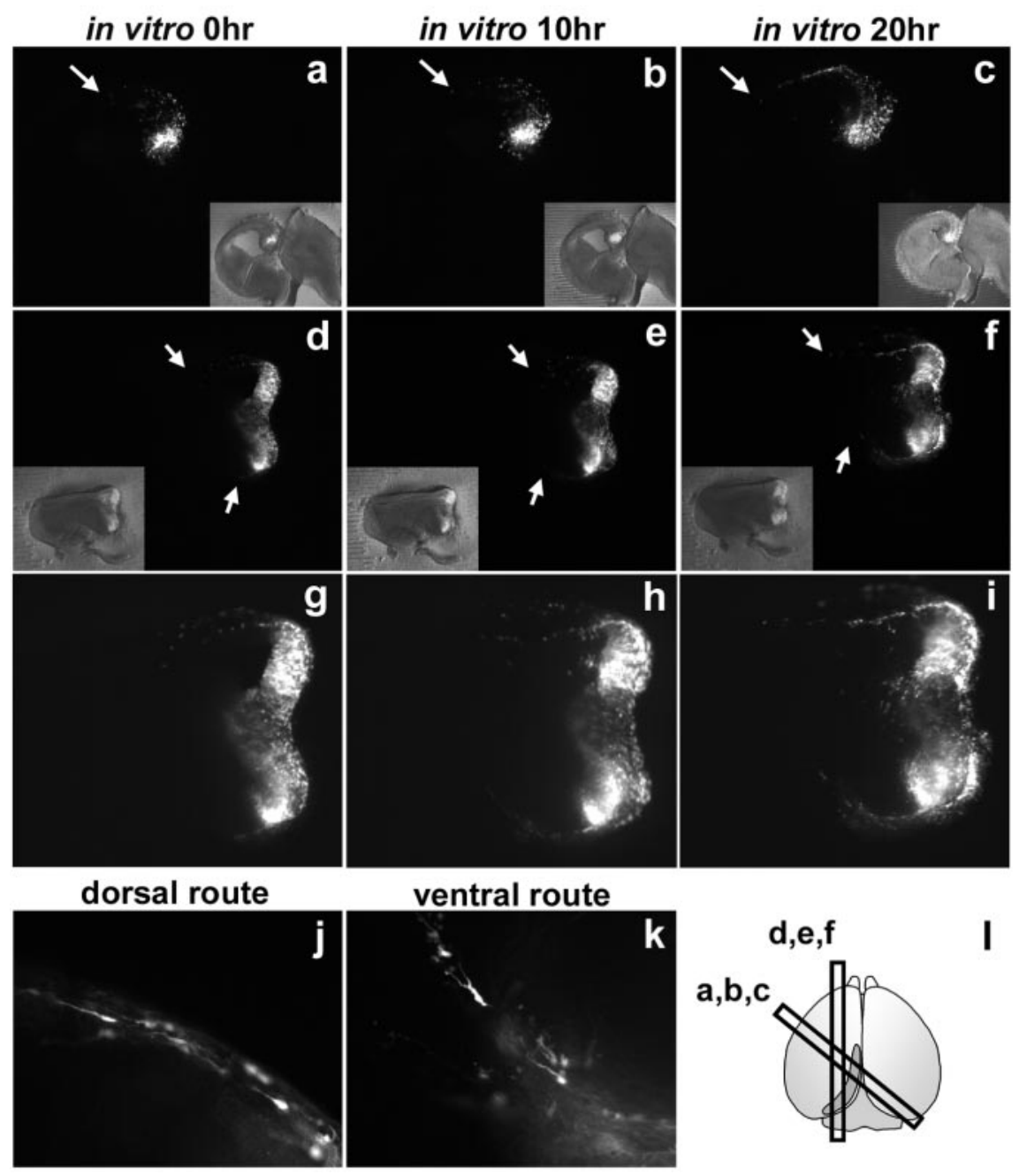

Figure 7. In vitro slice culture analyses on the origins and migratory pathway of CMWT-derived descendants. $a-i$, Images obtained after $0 \mathrm{hr}(a, d, g), 10 \mathrm{hr}(b, e, h)$, and $20 \mathrm{hr}(c, f, i)$ of in vitro slice cultures prepared from caudomedial-rostrolateral sections $(a-c)$ and posterior-anterior sections $(d-i)$. Insets $(a-f)$ show the merged images of fluorescent and bright field. $g-i$, High-power views of $d-f$. $j, k$, Tangentially migrating GFP-positive descendants on dorsal $(g)$, and ventral $(h)$ routes. $l$, A diagram showing the way slices were prepared through the electroporated regions at the CMWT. Arrows $(a-f)$ show the extent of tangential migration. Images are representative of 19 slices obtained from eight electroporated samples.

terior-anterior, or caudomedial-rostrolateral axis of the cerebral cortex through the CMWT where the electroporation-mediated gene transfer was conducted, and asked which slices were preferred by the CMWTderived GFP-positive descendants to tangentially migrate in the $\mathrm{MZ}$ in vitro.

In slice cultures prepared from the sections along the dorsolateral axis, GFP-positive descendants did not migrate along the cortical surface over the $24 \mathrm{hr}$ of the culture period (data not shown). In contrast, in slice cultures from sections along either the caudomedial-rostrolateral or posterior-anterior axis, many tangentially migrating descendants from the CMWT were detected along the cortical surface of the prospective neocortex over the $20 \mathrm{hr}$ of the culture period (Fig. 7a-i). At the time of isolation only a few GFP-expressing descendants were detected at the prospective neocortex (Fig. $7 a, d, g$ ). The number of descendants increased markedly after $10 \mathrm{hr}$ (Fig. $7 b, e, h$ ), and the population extended from medial to lateral along the cortical surface over $20 \mathrm{hr}$ of culture period (Fig. $7 c, f, i)$. Dorsal and ventral migratory routes in an overall posterior-anterior direction were recognizable, which was consistent with the results obtained from the in vivo studies (Fig.
$7 a-i)$. Forwardly extended tangentially oriented neurites tailed by the following cell bodies, a characteristic feature of migrating cells, were detected in both dorsal (Fig. 7j) and ventral (Fig. $7 k$ ) route of migration.

Thus, these in vitro slice culture experiments provide prospective and direct evidence that progenitor cells located at the CMWT at E11.5 generate descendants that tangentially migrate on the neocortical surface. Moreover, these studies suggest that the CMWT-derived descendants take an overall posterior-anterior directed pathway on the neocortical surface along the caudomedial-rostrolateral axis and posterioranterior axis, but not preferentially along the dorsolateral axis of the cerebral cortex.

\section{Discussion}

Present studies address three major points on the issues dealing with the ontogeny of reelin-positive MZ cells: (1) The CMWT, including the cortical hem, appears to be a source for the generation of prospective reelin-positive cells. (2) The CMWTderived reelin-positive cells tangentially migrate at the cortical $\mathrm{MZ}$ in an overall posterior-anterior direction. (3) These migrating neurons distribute in a caudomedial-high to rostrolateral-low cellular gradient throughout the entire neocortex during the peak period of corticogenesis.

Our results define neocortical reelinpositive marginal zone cells, in addition to neocortical interneurons (Anderson et al., 1997), as a neuronal subtype that tangentially migrates from locations extrinsic to the neocortex and participates in the neocortical organization. Unlike the migration of interneurons, it appears there is a strict preference in the migration of CMWT-derived reelin-positive cells in that these neurons migrate exclusively in the MZ. Furthermore, our findings define a population of neocortical reelin-positive cells as a subclass of reelin-positive cells derived commonly from the CMWT and distributed throughout the entire cerebral cortical MZ.

\section{Differential reelin-positive cell marker expression and the} heterogeneity of reelin-positive cells

We first consider the relationship between the GFP expression and reelin-positive cells in $\mathrm{Tg}$ mouse embryos. Previous studies on the analyses of early expression patterns of reelin-positive cell markers raised the possibility that reelin-positive cells are generated from several putative sources in the telencephalon (Schiffmann et al., 1997; Alcantara et al., 1998). Our results presented above indicate that GFP transgene, in addition to reelin and p73, serves as another reliable marker for the identification of reelinpositive cells that are located in $\mathrm{Tg}$ embryonic neocortical MZ. The spatial and temporal correlations between the expressions of GFP with those of reelin and $p 73$ from the early onset of reelinpositive cell development suggest that GFP expression and reelin- 
positive cell lineage might be cohesive throughout the embryonic cerebral cortical development. By recruiting GFP, we defined the CMWT as the telencephalic region where reelin-positive cell markers are most prominently expressed at the time when most reelin-positive cells are generated, suggesting that this location is a site where prospective reelin-positive cells are generated. Furthermore, at the dorsal and ventral regions of CMWT, the onset of GFP expression is followed by those of reelin and $p 73$ differentially, suggesting the existence of heterogeneity of prospective reelin-positive cells that might be distinguished by the differential temporal patterns of reelin-positive cell marker expressions.

\section{Origins of reelin-positive cells in the telencephalon}

Our studies on the early expression patterns of reelin-positive cell markers, as with the previous studies, however, do not resolve whether the cells located at putative sources give rise to reelinpositive cells during the cerebral cortical development. By using electroporation-mediated gene transfer (Miyasaka et al., 1999; Saito and Nakatsuji, 2001; Tabata and Nakajima, 2001; Hatanaka and Murakami, 2002), we show here, as expected, prospective reelin-positive cells are generated at the CMWT, including the cortical hem at E11.5. Moreover, it appears the CMWT-derived descendants at the cerebral cortex are solely dedicated to reelinpositive cells. In contrast, the other regions of telencephalon, including the neocortical primordium, where the electroporation was conducted appear to give rise to a few, if any, reelinpositive cells at E11.5. Taking into account of the fact that the prominent expressions of reelin-positive cell markers, including the GFP transgene, are detected focally at the CMWT but not at the other regions of telencephalon, these results indicate that the CMWT is a source for the generation of prospective neocortical reelin-positive cells, among telencephalic regions including neocortical primordium.

A study performed in the Emx1/2 knock-out mouse (Mallamaci et al., 2000; Shinozaki et al., 2002; Bishop et al., 2003), together with Emxl-expressing cell lineage study using Cre-loxP system (Gorski et al., 2002), shows that most reelin-positive cells are derived from Emx1-expressing progenitors, and Emx1/2 are required for both reelin-positive cell and subplate generation. On the contrary, a more recent study in the Sey mutant mouse was able to show that Pax6 appear to inhibit reelin-positive cell generation but not, interestingly, subplate generation (Stoykova et al., 2003). Given that Emx1/2 and Pax6 expression is in a graded manner in an opposite direction along the rostrolateral-caudomedial axis of the cerebral cortex (O'Leary and Nakagawa, 2002), these studies may imply that the generation of reelin-positive cells are regulated by opposing interactions between $E m \times 1 / 2$ and Pax6. Consistent with this idea, our results indicate that the caudomedially situated Emx1/2-high and Pax6-low region in the cerebral cortex, namely the CMWT, is spatially allocated for reelinpositive cell generation. Moreover, these mouse genetics studies suggest that the generation of reelin-positive cells and subplate is controlled commonly by Emx1/2, but differentially by Pax6. This is again consistent with our results showing that the CMWT-derived progenies tangentially migrating into the neocortex are solely dedicated to reelin-positive cells in the $\mathrm{MZ}$, indicating the generation of reelin-positive cell and subplate is differentially controlled.

\section{Tangential migratory behavior and distribution of reelin- positive cells at the neocortex}

Our detailed analyses of the electroporated location within the CMWT suggest the cortical hem serves as a source for reelinpositive cells. The cortical hem can be subdivided into two dis- tinct regions in terms of the initial migratory routes of their progenies. In addition, spatial and temporal analyses of expression patterns of GFP combined with those of reelin and $p 73$ at the CMWT revealed two distinct subregions within the locus. Taken together, it appears that prospective reelin-positive cells initially expressing p73 migrate dorsally from the dorsal region of the cortical hem, whereas prospective reelin-positive cells initially expressing GFP migrate ventrally from the ventral region of the cortical hem. These studies suggest differential migratory pathways are taken initially depending on the differential subgroups of prospective reelin-positive cells derived from differential origins at the cortical hem.

After exiting the CMWT, the prospective reelin-positive cells invade the neocortical area circumferentially from dorsal, ventral, and posterior directions and set up an overall posterioranterior cellular influx in the MZ. Our in vitro studies support the in vivo migratory results and further indicate that the CMWTderived reelin-positive cells tangentially migrate along the neocortical surface in an overall posterior-anterior direction. Given that apparent uniform localization of reelin-positive cells in the entire cortical MZ, other reelin-positive cell subtypes (e.g. subpial granule cells; see Meyer et al., 1998) may tangentially migrate in an opposite anterior-posterior direction. Thus, distinct reelinpositive cell subtypes generated at the distinct locations, including the ones generated at the dorsal and ventral regions of the cortical hem, might tangentially migrate to the cortical $\mathrm{MZ}$ in particular directions and comprise the entire population of reelin-positive cells in the cerebral cortex.

We do not know if distinct roles are played by reelin-positive cells derived from the distinct focal locations of the telencephalon in the control of organization of the neocortex. The prospective reelin-positive cells that have been generated at the CMWT at E11.5 cover the posterior half of the neocortex by E13.5, corresponding to the time when the generation of deep layer CP neurons is taking place (Polleux et al., 1997). These tangentially migrating reelin-positive marginal zone cells appear to be continuously supplied and cover the entire neocortical surface in a caudomedialrostrolateral gradient when a dimension tangential to the surface expands rapidly during the peak period of CP cell generation. Thus, reelin-positive cells extrinsic to the neocortex and $\mathrm{CP}$ cells intrinsic to the neocortex appear to intercross with each other at the neocortex and elicit coordinated interactions during the dynamic developmental period of corticogenesis. The spatially and temporally controlled tangential migration of reelin-positive marginal zone cells from the CMWT may therefore underlie the fundamental organization of the neocortex.

One of the most striking scenarios that might be uncovered as a consequence of the present study may concern the way regional or areal specification of the cerebral cortex is established (Grove and Fukuchi-Shimogori, 2003). The issue of areal specification of the neocortex has always raised the question of how cortical areas with enormous dimensions compared with the other regions in the central nervous system would be patterned by the simple diffusion of molecules from the localized signaling centers. Numerous lines of evidence indicate that interactions between the cells with distinct positional identities elicit further specification of the neural characters. The generation and tangential migration of reelin-positive marginal zone cells from one of the putative local signaling centers of the cerebral cortex, the cortical hem, provides an opportunity for the local signaling center to impose positional information onto cells intrinsic to the neocortex. Pertinent to this, the analysis of $G d f-7$ knock-in mice has revealed the existence of tangentially migrating $M Z$ cells in the 
Gdf-7-expressing lineage at the CMWT, which may correspond to the tangentially migrating reelin-positive marginal zone cells (Monuki et al., 2001). Whether reelin-positive marginal zone cells that are derived from the CMWT might be involved in the areal as well as laminar organization of developing neocortex awaits further studies.

\section{References}

Alcantara S, Ruiz M, D'Arcangelo G, Ezan F, de Lecea L, Curran T, Sotelo C, Soriano E (1998) Regional and cellular patterns of reelin mRNA expression in the forebrain of the developing and adult mouse. J Neurosci 18:7779-7799.

Anderson SA, Eisenstat DD, Shi L, Rubenstein JL (1997) Interneuron migration from basal forebrain to neocortex: dependence on Dlx genes. Science 278:474-476.

Arimatsu Y, Miyamoto M, Nihonmatsu I, Hirata K, Uratani Y, Hatanaka Y, Takiguchi-Hayashi K (1992) Early regional specification for a molecular neuronal phenotype in the rat neocortex. Proc Natl Acad Sci USA 89:8879-8883.

Arimatsu Y, Ishida M, Takiguchi-Hayashi K, Uratani Y (1999) Cerebral cortical specification by early potential restriction of progenitor cells and later phenotype control of postmitotic neurons. Development 126:629-638.

Bishop KM, Garel S, Nakagawa Y, Rubenstein JL, O’Leary DD (2003) Emx1 and $\mathrm{Emx} 2$ cooperate to regulate cortical size, lamination, neuronal differentiation, development of cortical efferents, and thalamocortical pathfinding. J Comp Neurol 457:345-360.

Gleeson JG, Walsh CA (2000) Neuronal migration disorders: from genetic diseases to developmental mechanisms. Trends Neurosci 23:352-359.

Gorski JA, Talley T, Qiu M, Puelles L, Rubenstein JL, Jones KR (2002) Cortical excitatory neurons and glia, but not GABAergic neurons, are produced in the Emx1-expressing lineage. J Neurosci 22:6309-6314.

Grove E, Fukuchi-Shimogori T (2003) Generating the cerebral cortical area map. Annu Rev Neurosci 26:355-380.

Grove EA, Tole S, Limon J, Yip L, Ragsdale CW (1998) The hem of the embryonic cerebral cortex is defined by the expression of multiple Wnt genes and is compromised in Gli3-deficient mice. Development 125:2315-2325.

Gupta A, Tsai LH, Wynshaw-Boris A (2002) Life is a journey: a genetic look at neocortical development. Nat Rev Genet 3:342-355.

Hatanaka Y, Murakami F (2002) In vitro analysis of the origin, migratory behavior, and maturation of cortical pyramidal cells. J Comp Neurol 454:1-14.

Hevner RF, Neogi T, Englund C, Daza RA, Fink A (2003) Cajal-Retzius cells in the mouse: transcription factors, neurotransmitters, and birthdays suggest a pallial origin. Brain Res Dev Brain Res 141:39-53.

Imam SA, Young L, Chaiwun B, Taylor CR (1995) Comparison of two microwave based antigen-retrieval solutions in unmasking epitopes in formalin-fixed tissue for immunostaining. Anticancer Res 15:1153-1158.

Ishibashi M, Ang SL, Shiota K, Nakanishi S, Kageyama R, Guillemot F (1995) Targeted disruption of mammalian hairy and Enhancer of split homolog-1 (HES-1) leads to up-regulation of neural helix-loop-helix factors, premature neurogenesis, and severe neural tube defects. Genes Dev 9:3136-3148.

Lavdas AA, Grigoriou M, Pachnis V, Parnavelas JG (1999) The medial ganglionic eminence gives rise to a population of early neurons in the developing cerebral cortex. J Neurosci 19:7881-7888.

Mallamaci A, Mercurio S, Muzio L, Cecchi C, Pardini CL, Gruss P, Boncinelli E (2000) The lack of Emx2 causes impairment of reelin signaling and defects of neuronal migration in the developing cerebral cortex. J Neurosci 20:1109-1118.

Marín-Padilla M (1978) Dual origin of the mammalian neocortex and evolution of the cortical plate. Anat Embryol (Berl) 152:109-126.

Marín-Padilla M (1998) Cajal-Retzius cells and the development of the neocortex. Trends Neurosci 21:64-71.

Meyer G, Soria JM, Martinez-Galan JR, Martin-Clemente B, Fairen A (1998) Different origins and developmental histories of transient neurons in the marginal zone of the fetal and neonatal rat cortex. J Comp Neurol 397:493-518.

Meyer G, Goffinet AM, Fairen A (1999) What is a Cajal-Retzius cell? A reassessment of a classical cell type based on recent observations in the developing neocortex. Cereb Cortex 9:765-775.
Meyer G, Schaaps JP, Moreau L, Goffinet AM (2000) Embryonic and early fetal development of the human neocortex. J Neurosci 20:1858-1868.

Meyer G, Perez-Garcia CG, Abraham H, Caput D (2002) Expression of p73 and reelin in the developing human cortex. J Neurosci 22:4973-4986.

Miyasaka N, Arimatsu Y, Takiguchihayashi K (1999) Foreign gene expression in an organotypic culture of cortical anlage after in vivo electroporation. NeuroReport 10:2319-2323.

Monuki ES, Porter FD, Walsh CA (2001) Patterning of the dorsal telencephalon and cerebral cortex by a roof plate-Lhx2 pathway. Neuron 32:591-604.

Motoyama J, Kitajima K, Kojima M, Kondo S, Takeuchi T (1997) Organogenesis of the liver, thymus and spleen is affected in jumonji mutant mice. Mech Dev 66:27-37.

Muneoka K, Wanek N, Bryant SV (1986a) Mouse embryos develop normally exo utero. J Exp Zool 239:289-293.

Muneoka K, Wanek N, Bryant SV (1986b) Exo utero survival of mouse embryos. Prog Clin Biol Res 217A:305-308.

Nadarajah B, Parnavelas JG (2002) Modes of neuronal migration in the developing cerebral cortex. Nat Rev Neurosci 3:423-432.

Ngo-Muller V, Muneoka K (2000) Exo utero surgery. Methods Mol Biol 135:481-492.

Ogawa M, Miyata T, Nakajima K, Yagyu K, Seike M, Ikenaka K, Yamamoto H, Mikoshiba K (1995) The reeler gene-associated antigen on CajalRetzius neurons is a crucial molecule for laminar organization of cortical neurons. Neuron 14:899-912.

O'Leary DD, Nakagawa Y (2002) Patterning centers, regulatory genes and extrinsic mechanisms controlling arealization of the neocortex. Curr Opin Neurobiol 12:14-25.

Polleux F, Dehay C, Kennedy H (1997) The timetable of laminar neurogenesis contributes to the specification of cortical areas in mouse isocortex. J Comp Neurol 385:95-116.

Rice DS, Curran T (2001) Role of the reelin signaling pathway in central nervous system development. Annu Rev Neurosci 24:1005-1039.

Saito T, Nakatsuji N (2001) Efficient gene transfer into the embryonic mouse brain using in vivo electroporation. Dev Biol 240:237-246.

Schaeren-Wiemers N, Gerfin-Moser A (1993) A single protocol to detect transcripts of various types and expression levels in neural tissue and cultured cells: in situ hybridization using digoxigenin-labelled cRNA probes. Histochemistry 100:431-440.

Schiffmann SN, Bernier B, Goffinet AM (1997) reelin mRNA expression during mouse brain development. Eur J Neurosci 9:1055-1071.

Shinozaki K, Miyagi T, Yoshida M, Miyata T, Ogawa M, Aizawa S, Suda Y (2002) Absence of Cajal-Retzius cells and subplate neurons associated with defects of tangential cell migration from ganglionic eminence in Emx1/2 double mutant cerebral cortex. Development 129:3479-3492.

Soda T, Nakashima R, Watanabe D, Nakajima K, Pastan I, Nakanishi S (2003) Segregation and coactivation of developing neocortical layer 1 neurons. J Neurosci 23:6272-6279.

Stoykova A, Hatano O, Gruss P, Gotz M (2003) Increase in reelin-positive cells in the marginal zone of Pax6 mutant mouse cortex. Cereb Cortex 13:560-571.

Supèr H, Soriano E, Uylings HB (1998) The functions of the preplate in development and evolution of the neocortex and hippocampus. Brain Res Brain Res Rev 27:40-64.

Tabata H, Nakajima K (2001) Efficient in utero gene transfer system to the developing mouse brain using electroporation: visualization of neuronal migration in the developing cortex. Neuroscience 103:865-872.

Takiguchi-Hayashi K, Sato M, Sugo N, Ishida M, Sato K, Uratani Y, Arimatsu Y (1998) Latexin expression in smaller diameter primary sensory neurons in the rat. Brain Res 801:9-20.

Tissir F, Goffinet AM (2003) reelin and brain development. Nat Rev Neurosci 4:496-505.

Watanabe D, Inokawa H, Hashimoto K, Suzuki N, Kano M, Shigemoto R, Hirano T, Toyama K, Kaneko S, Yokoi M, Moriyoshi K, Suzuki M, Kobayashi K, Nagatsu T, Kreitman RJ, Pastan I, Nakanishi S (1998) Ablation of cerebellar Golgi cells disrupts synaptic integration involving GABA inhibition and NMDA receptor activation in motor coordination. Cell 95:17-27.

Wood JG, Martin S, Price DJ (1992) Evidence that the earliest generated cells of the murine cerebral cortex form a transient population in the subplate and marginal zone. Brain Res Dev Brain Res 66: 137-140. 